\title{
The Social Determinants of Mental Health: A Descriptive Study of State Mental Health Agencies' Priorities
}

\author{
Merrill Rotter $^{1}\left(\mathbb{D} \cdot\right.$ Michael Compton $^{2} \cdot$ Dhanushki Samaranayake $^{3} \cdot$ Amy Ehntholt $^{4} \cdot$ Emily Baldwin $^{3}$. \\ Lynne Schaeffer ${ }^{3}$. Suzanne Feeney ${ }^{3} \cdot$ Thomas E. Smith $^{2}$
}

Received: 24 January 2021 / Accepted: 16 November 2021 / Published online: 21 January 2022

(c) The Author(s), under exclusive licence to Springer Science+Business Media, LLC, part of Springer Nature 2021

\begin{abstract}
Social determinants are receiving renewed attention as research demonstrates the effects of social factors on individuals' physical and mental health and elucidates the biological and psychological mechanisms underlying those effects. Through spheres of influence from policy and regulation development to direct service provision, state mental health agencies are in a unique position to lead primary and secondary prevention efforts aimed at addressing social determinants with both clientlevel and structural-level interventions. A survey of social determinants-related activity was sent to the Medical Directors of the state offices of mental health in all 50 states. The survey results suggest consensus among respondents as to the importance of addressing specific social determinants. However, few state mental health agencies have taken on a comprehensive and intentional approach to addressing social determinants as a unique area of activity. Specific activities are reviewed, and implications for future work is discussed.
\end{abstract}

Keywords Social determinants $\cdot$ Policies $\cdot$ Regulations $\cdot$ State mental health agencies $\cdot$ Screening

\section{Introduction}

Almost 80 years ago, the Constitution of the World Health Organization (WHO) recognized that "health is a state of complete physical, mental and social well-being and not merely the absence of disease or infirmity" (WHO Constitution, 1946). Some 40 years later, Engel, in describing the "biopsychosocial" approach to addressing mental illnesses, wrote, "to best serve the patient, higher-system-level

Merrill Rotter

merrill.rotter@omh.ny.gov

Michael Compton

mtc2176@cumc.columbia.edu

Dhanushki Samaranayake

dhanushki.samaranayake@omh.ny.gov

Amy Ehntholt

amy.ehntholt@nyspi.columbia.edu

Emily Baldwin

emily.baldwin@omh.ny.gov

Lynne Schaeffer

lynne.schaeffer@omh.ny.gov

Suzanne Feeney

suzanne.feeney@omh.ny.gov occurrences must be approached...the physician identifies and evaluates the stabilizing and destabilizing potential of events and relationships in the patient's social environment..." (Engel, 1978). The social history, in which clinicians document the social adversities facing clients, particularly housing issues or educational and employment challenges, has long been part of routine intake assessments and treatment planning. More recently, the relevance of trauma, including childhood trauma and the chronic stress

Thomas E. Smith

thomas.smith@nyspi.columbia.edu

1 Bronx Psychiatric Center, NYS Office of Mental Health, Albert Einstein College of Medicine, 1500 Waters Place, Bronx, NY 10461, USA

2 New York State Psychiatric Institute, Columbia University Vagelos College of Physicians and Surgeons, 1051 Riverside Drive, Unit 100, New York, NY 10032, USA

3 NYS Office of Mental Health, 44 Holland Avenue, Albany, NY 12229, USA

4 NYS Office of Mental Health, New York State Psychiatric Institute, 1051 Riverside Drive, Unit 100, New York, NY 10032, USA 
and trauma of interpersonal and systemic racism, have been recognized as critically influencing mental health and mental illnesses (Brown et al., 2000; Nurius et al., 2012). The paradigm of social determinants is receiving renewed attention at the federal and local levels, as research demonstrates the effects of social and environmental factors on individuals' physical and mental health, and elucidates the biological and psychological mechanisms underlying those effects (Compton \& Shim, 2015; Healthy People, 2030; Tuskeviciute et al., 2019).

The WHO defines the social determinants of health (SDH) as "the conditions in which people are born, grow, live, work and age that affect health and the rates of illnesses within populations...these circumstances are shaped by the distribution of money, power and resources at global, national and local levels" (WHO Constitution, 1946). These factors include those in the socioeconomic sphere, such as education and employment; basic needs such as housing and food; diverse forms of violence and discrimination; and environmental issues such as neighborhood disorder and pollution (Fig. 1). These conditions can also have a negative effect on mental health; because of the chronic stress that they cause. Furthermore, adverse social conditions are both risk factors for and consequences of behavioral disorders like serious mental illnesses and substance use disorders (Compton \& Shim, 2015). This creates a harmful feedback loop in which social adversities negatively impact the course and outcomes of an individual's behavioral disorder, which in turn reinforces or magnifies the already existing social challenges.
During the COVID-19 pandemic, excessive disease burden was observed among already disadvantaged populations, and the social gradient in physical and mental health was vividly and tragically demonstrated (Bernardini et al., 2021). The pandemic-related economic uncertainty, which included financial hardship for many and potential for significant social service cuts despite increased need, made the humanitarian and the fiscal arguments for addressing adverse social conditions even more apparent (Pruitt et al., 2018).

Even before the pandemic, policymakers had begun to emphasize the importance of the social determinants of health, as exemplified by New York State's proposal for a Health Across All Policies approach (NYS State of the State, 2017). In the clinical sector in particular, the New York State Department of Health created a Bureau of Social Determinants, with a focus on incorporating social determinants into care delivery initiatives such as care coordination in the Health Home program and planning and policy for value-based payments. Despite the clear overrepresentation of people with behavioral health disorders among individuals with the greatest general health service utilization (Sterling et al., 2018) and the direct relevance of social conditions for behavioral health outcomes, state mental health policy has focused on providing and/or regulating the delivery of treatment, rather than supporting initiatives to include social determinants in a comprehensive prevention approach. With that in mind, the New York State Office of Mental Healththe State's mental health authority-established a Social Determinants of Mental Health (SDMH) Workgroup, with representatives from various bureaus and divisions within
Fig. 1 Social determinants of health

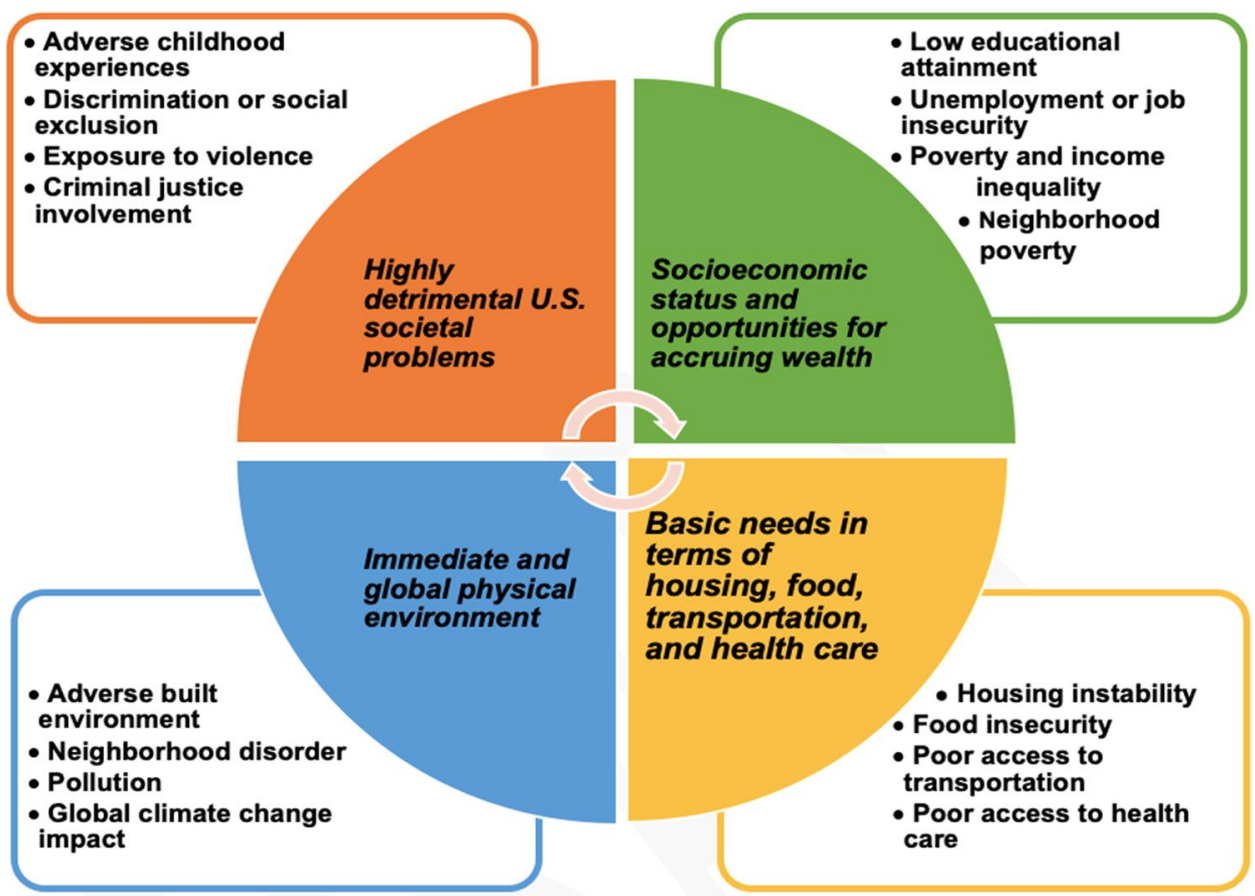


the agency. The Workgroup's mission is to identify opportunities for the agency to incorporate a social determinants focus from data analysis to policymaking, and from direct provision of care to regulatory oversight of mental health services (Fig. 2) (Rotter \& Compton, 2020). One of the initial recommendations of the Workgroup - which has since evolved into the Office of Prevention and Health Initiatives-was to survey the field to get a better understanding of the ways in which other state mental health agencies are approaching this critical area of clinical practice and structural change.

Several states have implemented policies within their Medicaid managed care programs, with models including mandated screening by managed care organizations and/or local services, requirements for social determinant interventions through value-based payment arrangements, and funding for social needs-focused services. These initiatives, however, are not necessarily under the auspices of the state mental health authority. To our knowledge, there has not been a reported survey of state mental health agencies' social determinants-related activities. Given the relationship between behavioral health and social and environmental conditions, we undertook this descriptive study as an attempt to begin to fill that gap.

\section{Methods}

\section{Survey Development and Dissemination}

The National State Mental Health Authorities SDMH Survey had the goal of beginning to understand what other state mental health agencies are doing in the SDMH area

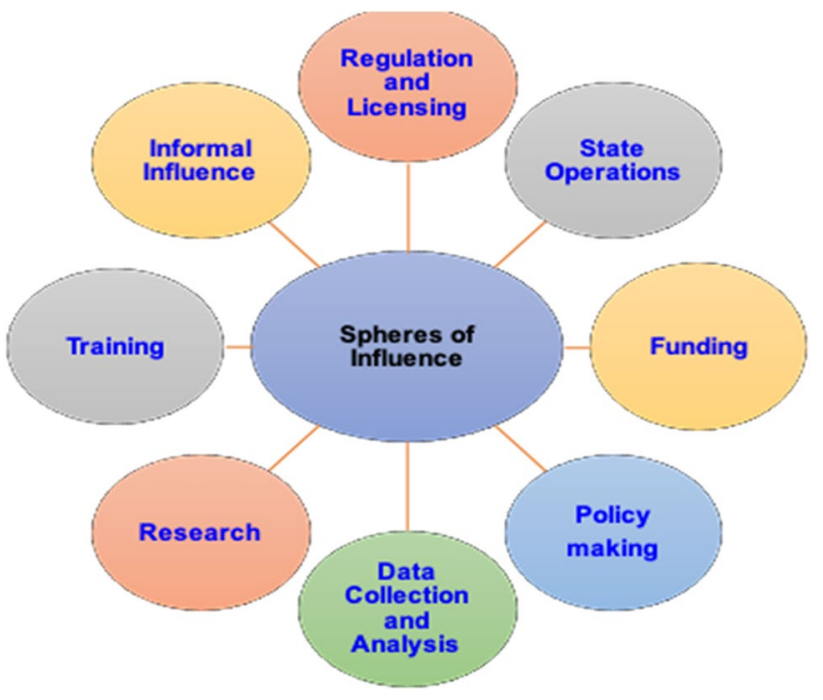

and to use that information to understand national trends, opportunities, and challenges. The mental health agencies of all 50 states were invited to participate.

The survey was developed based on the spheres of influence (i.e., areas in which the agency has power or ability to affect events and developments within the mental health services arena, across the state) described in the New York State Office of Mental Health SDMH White Paper (Rotter \& Compton, 2020). The survey prompted respondents to identify the spheres of influence most relevant to SDMH in their own states, from a list of options that included: regulation and licensing, state-operated services, funding, policymaking, data collection and analysis, research, training, and informal influence. These spheres of influence were clearly defined in the survey for the respondents.

The remaining questions were designed to identify ongoing SDMH efforts, related collaborations, and plans to sustain these efforts in the responding states. Survey respondents were first asked whether or not, in their capacity as a regulating and/or licensing agency, they had recommended or mandated that attention be given specifically to the social determinants of mental health. They were then asked if they recommended or mandated a specific screening tool pertaining to the SDMH as well as a specific response to a positive screen. These two questions allowed respondents to name any specific screening tool(s) and response activities (response options for the latter: "social/health navigation support," "use or creation of social needs-related directories," or "other, please specify"), if relevant. Alternatively, the survey allowed respondents to skip these items if they were deemed not applicable. The survey also obtained information about the existence of agency funding for social determinantsrelated activities; agency workgroups to address SDMH; collaboration with other state agencies to meet the social needs of clients or to develop primary prevention policies and initiatives; participation in activities that target awareness and mitigation of social determinants in the community at large; and statewide data collection, research, and training related to SDMH.

To identify the social determinants receiving the greatest attention from state mental health agencies, respondents were asked to select from $15 \mathrm{SDMH}$ their top five targeted ones. For each of the social factors chosen, survey participants were then prompted to identify the types of activities in place: screening, intervention, agency policy, cross-agency collaboration, funding for initiatives, and research/training. Respondents were also given the opportunity to describe their SDMH efforts in more detail, and to state the biggest challenges encountered.

Fig. 2 State mental health agency spheres of influence 


\section{Recruitment}

The survey was disseminated using Alchemer, an online survey software platform. Medical Directors (or designees) of the state mental health authorities in all 50 states were invited to participate. The survey was launched March 4, 2020, with dissemination beginning with outreach via the National Association of State Mental Health Program Directors (NASMPD) listserv. A description of the survey and invitations were mailed to Medical Directors who did not respond to the survey, after a reminder was sent through the listserv. Follow-up phone calls were made to invitees who did not respond to the mailed invitation. Successful phone contact was followed by individual email invitations with a link to the survey online, if requested. A second round of follow-up phone and email outreach to non-respondents was made throughout the summer and early fall of 2020. The survey remained open until October 19,2020 , to collect as many responses as possible.

\section{Data Analysis}

Some inclusion criteria were used for multiple submissions. If multiple survey submissions were made by a state (i.e., responses were begun on one date and then resumed or started again from the beginning on a later date), the most complete submission was selected for analysis. If multiple survey submissions were complete, the most recent submission was selected. If a survey was only partially completed, the completed responses were included in the analysis; for the analysis of the remaining (incomplete) responses, these states were excluded from the sample (i.e., were not included in the denominator). Descriptive statistics on the response data were performed using Microsoft Excel.

The authors certify that they have no conflicts of interest and take responsibility for the study and contents of this article.

\section{Results}

\section{Spheres of Influence}

Survey submissions were obtained from 26 states. Of those, more than $90 \%$ named the following as among their spheres of influence: funding, policymaking, and data collection and analysis. Between 75 and $90 \%$ of respondents also identified: regulation, training, state-operated services, and informal influence. The least commonly named sphere $(61.5 \%)$ was research.

\section{SDMH-Related Activities}

As shown in Table 1, two-thirds of the 26 respondents reported that their state agency recommended or mandated attention be paid to the SDMH; however, only $15 \%$ either endorsed a specific tool for screening or a specific action to address an identified social determinant. Fifteen states (68.2\%) reported providing some funding for SDMHrelated activities and almost two-thirds reported collecting SDMH-related data. Nearly all respondents were involved in community-related SDMH awareness-raising $(81.8 \%$, $\mathrm{n}=21$ ) and collaboration with other agencies to meet the social needs of clients (95.5\%, $\mathrm{n}=25)$, or to develop primary prevention policies and initiatives $(86.4 \%, \mathrm{n}=22)$; yet less than half had an identified SDMH-focused workgroup within their agency.

\section{Top Five SDMHs Being Addressed}

Twenty-two states responded to the question asking them to name the top five social determinants their agency is addressing. The most frequently targeted social determinant was housing ( 19 states; $86.4 \%$ ), followed by health care access (16 states; $72.7 \%$ ) and criminal justice involvement (16 states; $72.7 \%$ ), limited social support (14 states; 63.6\%), adverse childhood experiences (14 states; 63.6\%), and unemployment (12 states; 54.5\%) (Table 2). Financial strain was identified by only 6 of the 22 states (27.3\%) responding to this question. Transportation limitations and discrimination were named by 4 and 3 states, respectively. The remaining social determinants (neighborhood safety, childcare needs, personal safety, food insecurity, and utility bills) were named by only one state each. No state reported addressing the issue of low education in its top five.

Figure 3 presents the proportions of responding state agencies $(n=19)$ reporting specific activities related to

Table 1 Types of SDMH activities reported by survey participants

\begin{tabular}{llrl}
\hline SDMH-related activities & $\begin{array}{l}\text { \% Yes (recom- } \\
\text { mended or } \\
\text { mandated) }\end{array}$ & \% No \% Skipped \\
& S5.5 & 4.5 & \\
\hline Social needs collaboration & 96.4 & 13.6 & \\
Primary prevention col- & 86.4 & & \\
$\quad$ laboration & & 18.2 & \\
Community awareness & 81.8 & 31.8 & \\
Funding & 68.2 & 34.6 & \\
General attention & 65.4 & 36.4 & \\
Data collection & 63.6 & 45.5 & \\
Research & 54.5 & 59.1 & \\
Workgroup & 40.9 & 46.2 & 38.5 \\
Specific response & 15.4 & 46.2 & 38.5 \\
Specific tool & 15.3 & & \\
\hline
\end{tabular}


Table 2 Top 5 social determinants identified as priority areas by survey participants

\begin{tabular}{ll}
\hline Top 5 SDMHs & $\mathrm{n}=22$ \\
\hline Housing & $86.4(19)$ \\
Health care access & $72.7(16)$ \\
Criminal justice & $72.7(16)$ \\
Limited social support & $63.6(14)$ \\
Adverse childhood experiences & $63.6(14)$ \\
Unemployment & $54.5(12)$ \\
Financial strain & $27.3(6)$ \\
Transportation & $18.2(4)$ \\
Discrimination & $13.6(3)$ \\
Neighborhood safety & $4.5(1)$ \\
Childcare needs & $4.5(1)$ \\
Personal safety & $4.5(1)$ \\
Food insecurity & $4.5(1)$ \\
\hline
\end{tabular}

housing instability, the SDMH most likely to be identified as a priority. The 19 states that responded regarding housing instability were highly likely to report screening $(89.5 \%)$, interventions $(84.2 \%)$, and funding for housing-related programs (94.7\%), but were less likely to have endorsed specific policies $(68.4 \%)$ or research activities $(47.4 \%)$.

\section{Discussion}

The survey results provide a descriptive sampling of activities across the states with regard to addressing specific social determinants of health. Some of the SDMH that were offered as choices are much more likely to be targeted by state mental health agencies than are others. The fact that some social determinants are being addressed more than others does not necessarily mean that a state is not targeting them. Discrimination, for example, was only indicated by $13.6 \%$ of respondents. However, it could be that those states are combatting discrimination as an equity or diversity issue, rather than through a social determinants lens.

That said, the results indicate that much more work must be done, even among those states who took the time to respond to the survey. While a majority of the responding 26 states were assessing housing needs of their clients, there were other critical social needs that were not identified among their top 5 priorities. For example, only one state reported prioritizing food insecurity, despite the wellestablished link between secure access to food and improved health and well-being (Gundersen \& Ziliak, 2015). Our survey results revealed a similar lack of attention devoted to other equally important issues, including education, personal and neighborhood safety, childcare needs, and ability to pay utility bills. Transportation needs and discrimination (as noted above) were also not an explicit primary focus of more than a handful of the responding agencies. More research is needed to understand the challenges or barriers for state mental health agencies in addressing these well-documented social determinants impacting mental health.

In general, most of the responding states either recommended or mandated that attention be paid to social determinants, and the vast majority also indicated that agency activities include awareness-raising and collaborating with other state agencies. However, few responding agencies have taken on a comprehensive and intentional approach to addressing social determinants as a unique area of activity, as might be indicated by establishment of a SDMH-focused division or workgroup, or by recommending or requiring use of a specific SDMH screening tool, or specific policies targeting a social determinant. This survey finding - the recognition of the relevance of social determinants, without a requirement

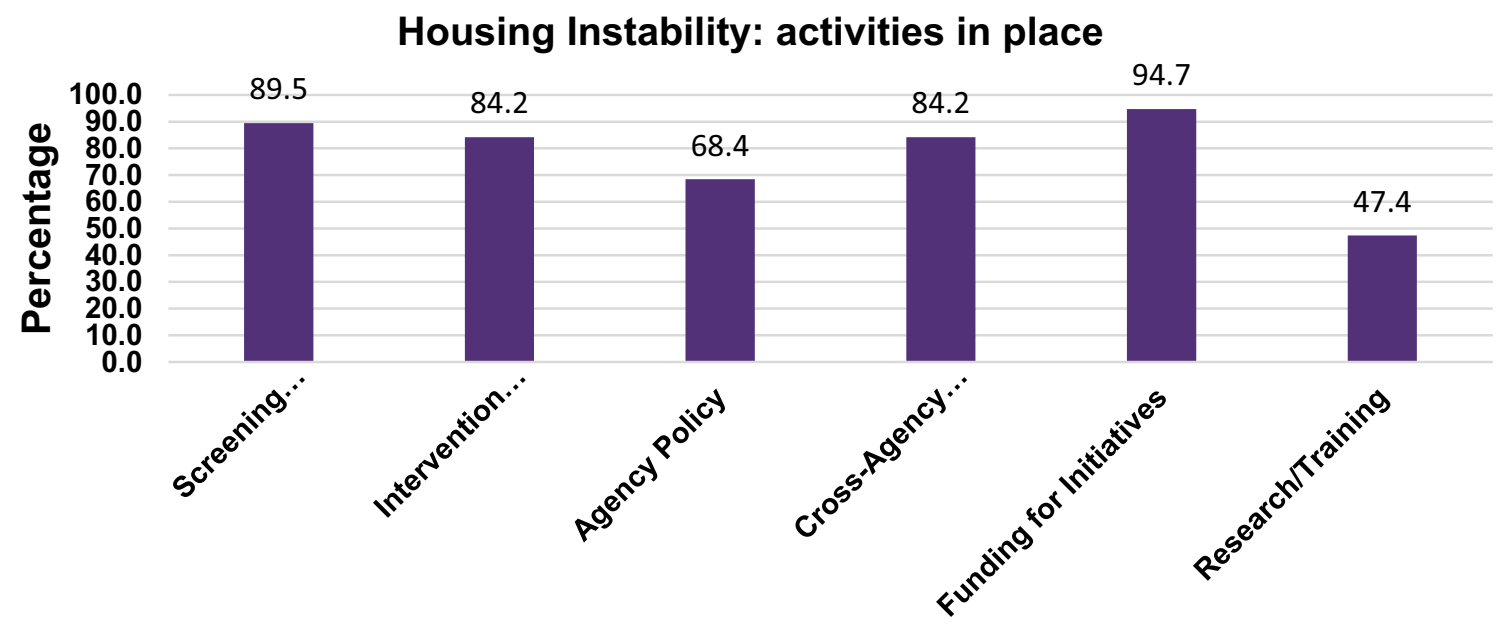

Fig. 3 Housing instability and spheres of influence 
for screening or intervention-is consistent with national approaches to social determinants. Several federal agencies, including the Centers for Disease Control and Prevention (CDC), the Substance Abuse and Mental Health Services Administration (SAMHSA), and the Centers for Medicare and Medicaid Services (CMS), have called attention to the importance of social determinants, with recommendations for implementation and training, but without clear mandates.

In the coming years, state mental health agencies will continue to be supported in, if not pushed into, addressing SDMH through expectations set by funders of mental health services at the federal and state level. For example, CMS launched the Accountable Health Communities (AHC) Model initiative in 2017 "based on emerging evidence that addressing health-related social needs through enhanced clinical-community linkages can improve health outcomes and reduce costs" (AHC Model, retrieved 2017). The pilot includes a screening tool covering 5 core domains of social determinants. Funding for this model is provided to support the infrastructure and staffing needs of grantee organizations, which develop a network of coordinated service providers, screening for social determinants with the standardized AHC tool, and care navigation. CMS AHC funds do not pay directly or indirectly for any community services. There are 29 participants across the country. As of December 2020, approximately one-third of over 480,000 screened beneficiaries had at least one of the "high risk social needs" (housing instability, utility difficulties, interpersonal violence, food insecurity, and transportation problems). Early findings, however, are mixed. Emergency department (ED) visits by Medicare fee-for-service beneficiaries declined by nine percent. However, while three-fourths of navigationeligible beneficiaries (i.e., those who have both at least one health-related social need and an ED visit in the year prior to enrollment) accepted navigation, only 14 percent had the identified need resolved, and approximately two-thirds were lost to follow-up (AHC Evaluation, 2020). In January 2021, CMS released a guidance document for states interested in developing programs that address social determinants of health, including overarching principles as well as services and supports that may be covered under Medicaid or other federal authorities (CMS SHO\# 21-001, 2021).

Several states already had this focus as part of their work. New Hampshire and Virginia, for example, require managed care organizations to screen and arrange for social determinants-related interventions (Medicaid Care Management Services Contract, 2019; Medallion 4.0 Managed Care Services Contract). Others (e.g., North Carolina) require managed care organizations to implement a standardized screening and then use Medicaid funding to cover SDH-related services (North Carolina's Healthy Opportunities Pilots, 2019). Ohio and New York also provide Medicaid funding for some SDH, such as transportation (Managed Care Plan
(MCP) Transportation Benefit Resource Guide). In New York, some SDH funding is part of an enhanced package of services for individuals with serious mental illnesses (Home and Community Based Services). Another model includes a requirement that one or more SDH is addressed as part of value-based payment reimbursement contracts (Final Report on State Strategies to Promote Value Based Payment through Medicaid Managed Care, 2020).

Finally, at the local level, even in the absence of a mandate, some managed care organizations, accountable care organizations, community behavioral health networks, and health care providers are including SDMH screening and intervention in their work process, sometimes with the support of an open or closed online network referral system (ConnexRX Inception Growth and Future Vision for a Network Focused Referral System, 2020; Henderson \& Lamantia, 2020).

Many of these federal, state, and local programmatic and funding initiatives have a broader health focus. However, the availability of reimbursement for SDMH interventions, increasing use of models of integration of treatment of health and mental health conditions, the special needs of individuals with serious mental illnesses regarding SDMH (e.g., those related to cognitive or other challenges), and the importance of addressing SDMH as an engagement activity, give these initiatives relevance for state mental health agencies as well.

Generalization and causal conclusions cannot be made from this limited study; our primary purpose was to provide a description of the SDMH activities among various state agencies. Just over 50\% of states responded, and among those that did, there were several states that did not complete the full survey. In addition, while the survey covered broad categories of social determinants, it is not always clear that respondents defined social determinants in the same way. In providing an example of a social determinant screening, one state cited the Child and Adolescent Needs and Strengths Assessment, which is not specifically a screen for social needs. Finally, although the survey did request feedback about cross-agency collaboration, it did not reveal to what extent, if any, such collaboration was limited to addressing client-level social needs or focused on addressing the structural level, i.e., the social norms and public policies that underpin SDMH (Compton \& Shim, 2015).

In summary, among responding state mental health agencies, there was broad concern about and awareness of the relevance of social determinants, but less unanimity was evident as to how to address them, which ones to address, and how much specific attention should be paid at the agency level. There remains a lack of standardization and centralization of approaches to addressing SDMH among state mental health authorities at both client and structural levels. 
While there is widespread interest in addressing clients' social needs for equity and fiscal reasons, the challenge is not just how to pay for these interventions, but also how to establish a coordinated approach, such as one that eliminates redundant assessment for both clients and providers, whether primary care, mental health, or social services. The availability of electronic information-sharing platforms makes such coordination a real possibility. The closed network model, in which physical health, mental health, and community services share an assessment and referral platform, is one way of maximizing the chances that clients will receive the services they need, and that all networked providers can know whether social determinants have been assessed and/ or addressed.

Social determinants-related initiatives, legislation, and policies-some clinical (such as health care access) and some not (such as those pertaining to housing, transportation, food, neighborhood safety) —often begin at the state level. State mental health agencies, therefore, have the potential to provide needed input into state planning, which will not only improve treatment, but will also begin to move the field toward primary prevention, and addressing social determinants at their core, in pursuit of fiscal efficiencies, improved health and health equity, and social justice. There are data that suggest that a social determinant focus as a primary intervention (related to housing, for example) can improve physical and mental health outcomes (Alegria et al., 2018); however, as discussed above, a more comprehensive focus on social determinants at the state level is only just emerging, so evidence on its effectiveness is needed. That said, while an economic and health outcomes argument can be made for prevention, social justice and health equity considerations provide immediate justification for this work. It is our hope that these initial survey findings advance our understanding of the gaps and opportunities.

\section{Appendix}

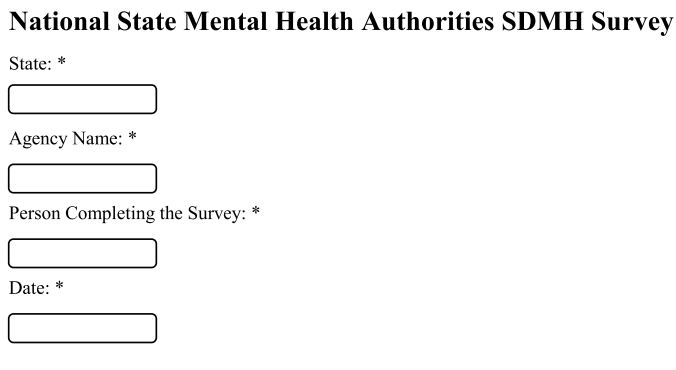

Introduction:

Given the critical and increasingly recognized importance of the social determinants of health, in August 2018, the New York State Office of Mental Health (NYS OMH) established a Social Determinants of Mental Health (SDMH) Workgroup to help define a social determinants agenda and coordinate with other state and local agencies. With this initiative in mind, NYS OMH is interested in getting a sense of what other state mental health agencies are doing in the SDMH area. To that end, we are asking for your assistance in completing the survey below, that will, we hope, give us information about national trends, opportunities, and challenges that we can share with others, as well. We hope to publish our findings, but in doing so will not name individual states unless we seek your approval first.

The survey is divided into the "spheres of influence" over which many state mental health agencies may have jurisdiction. Recognizing that states differ prominently, the survey begins by asking about your agency's spheres of influence, and then asks questions about activities within the spheres that are relevant in your state.

1. Which of the following spheres of influence are relevant for your state mental health agency? (Check all that apply) *

Regulation and Licensing: the oversight of inpatient, outpatient, and/or residential programs

$\square \quad$ State Operations: the provision of direct inpatient, outpatient, and/or residential services by the state mental health agency

$\square \quad$ Funding: providing initial or sustaining funding for specific initiatives, either directly or through local government

$\square \quad$ Policymaking: the setting of policy both within the agency and in conjunction with other state agencies and the state legislature

$\square \quad$ Data Collection and Analysis: aggregation of information (e.g., diagnostic, demographic, clinical, social, incidents) to inform program and policy analysis and planning

$\square \quad$ Research: collaboration with academic institutions, in support of research and dissemination activities, not necessarily tied to current clinical programs or operations

$\square \quad$ Training: including mandatory and/or elective training for the state operated mental health workforce, community-based workforce training, and conferences

$\square \quad$ Informal Influence: state mental health agency endorsement, encouragement, commendation, and other activities that carry weight (e.g., newsletters, public pronouncements, ad campaigns)

2. As a regulating and/or licensing agency, have you recommended or mandated specific attention to the social determinants of mental health? *

Y Yes, recommended

Y Yes, mandated

O No (skip to Q4.)

3ai. Have you recommended or mandated a specific screening tool pertaining to the social determinants of mental health; *

Y Yes, recommended

Y Yes, mandated

O No (skip to Q3bi.)

3aii. If yes, which screening tool(s):

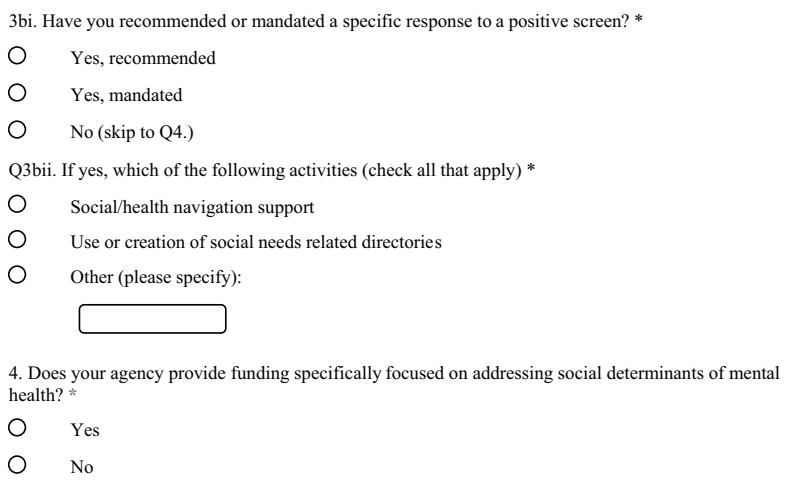


5. Has your agency established an entity (e.g., workgroup or bureau) to recommend new initiatives and/or policies for addressing social determinants of mental health?

○ Yes (please specify):

0 No

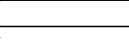

6. Is your agency collaborating with other state agencies to ensure that the social needs of the clients you serve are being met?

O Yes

No

7. Is your agency collaborating with other state agencies (including health and non-health agencies) in developing primary prevention policies and initiatives, i.e., those that address the social determinants that mitigate the risk of developing mental health issues; for example, addressing food insecurity and associated stresses? *

O Yes

No

8. Does your agency collect statewide data related to social determinants of mental health? *

O Yes

No

9. Does your agency support or initiate research and/or training related to social determinants of mental health? *

$\mathrm{O}$ Yes

O No

10. Does your agency participate in the promotion of activities and/or behaviors that target awareness and mitigation of social determinants in the community at large?

$\mathrm{O}$ Yes

O No

11. From the list below, check the top 5 social determinant items your agency addresses. *

$\square \quad$ Low Education

$\square \quad$ Unemployment/Job Insecurity

$\square \quad$ Financial Strain

$\square \quad$ Childcare Needs

$\square \quad$ Neighborhood Safety

$\square \quad$ Housing Instability

$\square \quad$ Utility Bills

$\square \quad$ Food Insecurity

$\square \quad$ Transportation Limitations

$\square \quad$ Discrimination

$\square \quad$ Limited Social Supports

$\square \quad$ Poor Access to Health Care

$\square \quad$ Personal Safety

$\square \quad$ Adverse Childhood Experiences

$\square \quad$ Criminal Justice Involvement

12. With reference to each of the social determinant items selected in Q11, which of the following activities does your agency have in place? Please check all the relevant boxes.

\begin{tabular}{|l|c|c|c|c|c|c|}
\hline $\begin{array}{c}\text { Auto- populated } \\
\text { per response to } \\
\text { Q11. }\end{array}$ & $\begin{array}{c}\text { Screening } \\
\text { (recommended } \\
\text { or required) }\end{array}$ & $\begin{array}{c}\text { Intervention } \\
\text { (recommended } \\
\text { or required) }\end{array}$ & $\begin{array}{c}\text { Agency } \\
\text { Policy }\end{array}$ & $\begin{array}{c}\text { Cross-Agency } \\
\text { Collaboration }\end{array}$ & $\begin{array}{c}\text { Funding } \\
\text { for } \\
\text { Initiatives }\end{array}$ & $\begin{array}{c}\text { Research/ } \\
\text { Training }\end{array}$ \\
\hline SD Item 1 & & & & & & \\
\hline SD Item 2 & & & & & & \\
\hline SD Item 3 & & & & & & \\
\hline SD Item 4 & & & & & & \\
\hline SD Item 5 & & & & & & \\
\hline
\end{tabular}

4. Please feel free to describe your SDMH effort(s) and biggest challenges in the area(s) in more deta in the space below.

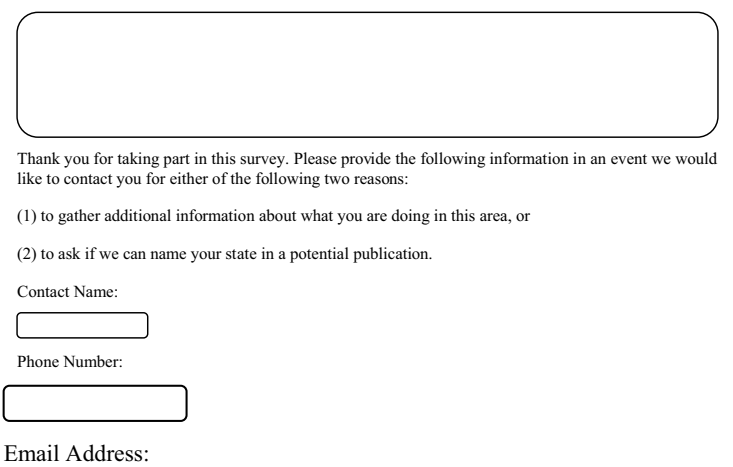

Funding No funding was received to assist with the preparation of this manuscript.

\section{Declarations}

Conflict of interest The authors have no conflicts of interest to declare that are relevant to the content of this article, and take responsibility for the study and contents of this article.

\section{References}

Accountable Health Communities Model. https://innovation.cms.gov/ innovation-models/ahcm. Accessed 24 Jan 2021.

Accountable Health Communities: Evaluation of Performance Years 1-3 (2017-2020). https://innovation.cms.gov/data-and-reports/ 2020/ahc-first-eval-rpt-fg. Accessed 24 Jan 2021.

Adult Behavioral Health Home and Community Based Services (BH HCBS). https://omh.ny.gov/omhweb/bho/hcbs.html. Accessed 24 Jan 2021.

Alegría, M., NeMoyer, A., FalgàsBagué, I., Wang, Y., \& Alvarez, K. (2018). Social determinants of mental health: Where we are and where we need to go. Current Psychiatry Reports, 20(11), 95. https://doi.org/10.1007/s11920-018-0969-9

Bernardini, F., Attademo, L., Rotter, M., \& Compton, M. T. (2021). Social determinants of mental health as mediators and moderators of the mental health impacts of the COVID-19 pandemic. Psychiatric Services, 72(5), 598-601.

Brown, T. N., Williams, D. R., Jackson, J. S., Neighbors, H. W., Torres, M., Sellers, S. L., \& Brown, K. T. (2000). "Being black and feeling blue": The mental health consequences of racial discrimination. Race and Society, 2(2), 117-131.

CMS SHO\# 21-001. (2021). RE: Opportunities in medicaid and CHIP to address social determinants of health (SDOH). https://www. medicaid.gov/federal-policy-guidance/downloads/sho21001.pdf. Accessed 24 Jan 2021.

Compton, M. T., \& Shim, R. S. (2015). The social determinants of mental health. American Psychiatric Publishing.

ConnexRX Inception Growth and Future Vision for a Network Focused Referral System. (2020). https://www.cbhsinc.org/post/9-paneldiscussion-connexrx-inception-growth-and-future-vision-for-anetwork-focused-referral-system. Accessed 24 Jan 2021.

Constitution of the World Health Organization. (1946). Constitution of the world health organization. American Journal of Public Health, 36(11), 1315-1323.

Engel, G. L. (1978). The biopsychosocial model and the education of health professionals. Annals of the New York Academy of Sciences, 310(1), 169-181.

Final Report on State Strategies to Promote Value Based Payment through Medicaid Managed Care. (2020). https://www.macpac. gov/wp-content/uploads/2020/03/Final-Report-on-State-Strat egies-to-Promote-Value-Based-Payment-through-MedicaidManaged-Care-Final-Report.pdf. Accessed 24 Jan 2021.

Gundersen, C., \& Ziliak, J. P. (2015). Food insecurity and health outcomes. Health Affairs (millwood), 34(11), 1830-1839. https://doi. org/10.1377/hlthaff.2015.0645

Healthy People 2030. https://health.gov/healthypeople/objectives-anddata/browse-objectives. Accessed 24 Jan 2021.

Henderson, J., \& Lamantia, J. (2020). New coordinated-care network seeks to alleviate Covid-19 burden. https://www.crainsnewyork. com/health-pulse/new-coordinated-care-network-seeks-alleviatecovid-19-burden. Accessed 24 Jan 2021. 
Managed Care Plan (MCP). Transportation benefit resource guide for practices. https://ohiopharmacists.org/aws/OPA/asset_manager/ get_file/518532. Accessed 24 Jan 2021.

Medallion 4.0 Managed Care Services Agreement. https://www.dmas. virginia.gov/files/links/5400/Medallion\%204.0\%20Contract\% 20SFY21v2.pdf. Accessed 24 Jan 2021.

Medicaid Care Management Services Contract. (2019). https://www. dhhs.nh.gov/business/rfp/documents/rfp-2019-oms-02-managexhibits.pdf. Accessed 24 Jan 2021.

New York State Ever Upward 2017 State of the State. https://www. governor.ny.gov/sites/default/files/atoms/files/2017StateoftheS tateBook.pdf. Accessed 24 Jan 2021.

North Carolina's healthy opportunities Pilots: A review of proposed design for interested stakeholders. https://files.nc.gov/ncdhhs/ documents/Healthy-Opportunities-Pilot_Policy-Paper_2_15_19. pdf. Accessed 24 Jan 2021.

Nurius, P. S., Logan-Greene, P., \& Green, S. (2012). Adverse childhood experiences (ACE) within a social disadvantage framework: Distinguishing unique, cumulative, and moderated contributions to adult mental health. Journal of Prevention \& Intervention in the Community, 40(4), 278-290.

Pruitt, Z., Emechebe, N., Quast, T., Taylor, P., \& Bryant, K. (2018). Expenditure reductions associated with a social service referral program. Population Health Management, 21(6), 469-476.
Social Determinants of Health (SDH) and Community Based Organizations (CBOs). https://www.health.ny.gov/health_care/medicaid/ redesign/sdh/sdh_bureauslides.htm. Accessed 24 Jan 2021.

Rotter M, Compton M. (2020) Social determinants of mental health: A white paper detailing promising practices and opportunities at the New York state office of mental health. A White Paper Detailing Promising Practices and Opportunities at the New York State Office of Mental Health

Sterling, S., Chi, F., Weisner, C., Grant, R., Pruzansky, A., Bui, S., Madvig, P., \& Pearl, R. (2018). Association of behavioral health factors and social determinants of health with high and persistently high healthcare costs. Preventive Medicine Reports, 11, 154-159.

Tuskeviciute, R., Hoenig, J., \& Norman, C. (2019). Social determinants of mental health among New York City adults. https://www1.nyc. gov/assets/doh/downloads/pdf/epi/databrief115.pdf. Accessed 24 Jan 2021.

Publisher's Note Springer Nature remains neutral with regard to jurisdictional claims in published maps and institutional affiliations. 